\title{
Studies on Pathogenicity of Potato cyst Nematode, Globodera rostochiensis and G. pallida on Potato
}

\author{
S. Vanitha ${ }^{1}$, A. Shanthi ${ }^{1 *}$, Priyank Hanuman Mhatre ${ }^{2}$, B. Anita ${ }^{1}$, \\ P. Kalaiarasan ${ }^{1}$, P. Marimuthu ${ }^{3}$ and M. Muthamilan ${ }^{4}$ \\ ${ }^{I}$ Department of Nematology, Tamil Nadu Agricultural University, \\ Coimbatore-03, Tamil Nadu, India \\ ${ }^{2}$ ICAR-Central Potato Research Station, Muthorai, Udhagamandalam- 643 004, India \\ ${ }^{3}$ Department of A griculture Microbiology, TNAU, Coimbatore -641 003, India \\ ${ }^{4}$ Department of Plant Pathology, TNAU, Coimbatore -641 003, India \\ *Corresponding author
}

\section{A B S T R A C T}

The pot culture experiments were conducted under polyhouse condition to study the pathogenicity of potato cyst nematode, Globodera rostochiensis and G. pallida on potato

\section{Keywords}

Pathogenicity, $G$. rostochiensis, $G$. pallida, Kufri Jyoti

Article Info

Accepted:

07 May 2019

Available Online:

10 June 2019 cv. Kufri Jyoti at different inoculum levels of $0,10,100,1000$ and 10,000 $\mathrm{J}_{2}$ per plant. The results revealed that, the potato cyst nematode Index was 4.0 at inoculum level of 10,000 $\mathrm{J}_{2} /$ plant and 1.75 at $10 \mathrm{~J}_{2}$ per plant. However, the reproduction factor was highest 215.61 with the lowest inoculum level of $10 \mathrm{~J}_{2} /$ plant where as $118.42,47.71$ and 22.02 respectively with the initial inoculum levels of 100,1000 and $10,000 \mathrm{~J}_{2}$ / plant. A gradual increase in the nematode inoculum levels declined the plant growth parameters progressively from 100 to 10,000 second stage juveniles $\left(\mathbf{J}_{2}\right)$ per plant. The highest reduction in plant growth was recorded at a level of $10,000 \mathrm{~J}_{2} /$ plant and the minimum was recorded at a level of $100 \mathrm{~J}_{2}$ /plant, where as $1000 \mathrm{~J}_{2}$ /plant recorded as an Economic Threshold Level. Inoculation of $1000 \mathrm{~J}_{2}$ /plant showed 40.60, 32.00, 40.07 and 70.20 per cent reduction in plant height, fresh weight, dry weight and yield per plant compared to uninoculated control. The maximum of $87.35 \%$ yield reduction was recorded, at an inoculum level of $10,000 \mathrm{~J}_{2}$ /plant followed by 70.20 and $27.00 \%$ at a levels of 1000 and $100 \mathrm{~J}_{2}$ /plant respectively.

\section{Introduction}

Potato (Solanum tuberosum L.) is one of the most important cash crops in the Nilgiris and Kodaikanal hills of Tamil Nadu. The major constraints in potato production are pests, nematodes and diseases which account for nearly $37 \%$ yield loss throughout the Globe, of which the share of diseases and nematodes alone is 23\% (Sasser and Freckman, 1987). Primarily, the potato cyst nematode and root knot nematode are important among plant parasitic nematodes associated with the potato rhizhospere in India. Among the plant parasitic nematodes, the potato cyst nematodes (PCN), Globodera spp. occupied a 
position of high economic importance (Trudgill et al., 2003). The demand of nutrition increases with the reproductive phase of nematode. This causes a huge yield losses ranging from $10 \%$ to $75 \%$ (Trudgill, 1986). Because of their adverse effect on the quality and quantity of tubers, easy transmission and difficulties in eradication has made this pest as the big hurdle in potato cultivation across the world. Thus both of these species are therefore included in the list of domestic as well as International Quarantine pathogens of many countries including India (Mhatre et al., 2019).

Several studies showed the presence of potato cyst nematodes in soil from potato cultivated fields around the Nilgiris and Kodaikanal hills of Tamil Nadu, India (Jones 1964; Thangaraju, 1983; Seenivasan et al., 2017). Also the presence of potato cyst nematodes from North Indian state, Himachal Pradesh was reported first time by Singh et al., (2010). Now potato cyst nematodes became an important biotic constraint in sustainable production of potato as very recently $\left(12^{\text {th }}\right.$ October 2018) govt. of India imposed a domestic quarantine on Himachal Pradesh, Uttarakhand, Jammu and Kashmir along with Tamil Nadu and restricted the sale of seed potatoes outside these states due to presence of potato cyst nematodes (Mhatre et al., 2019).

The association of potato cyst nematodes usually showed stunting of plants, chlorosis of leaves, poorly developed root system, small sized tubers and presence of potato cyst nematodes cysts in soil. In spite of these widespread distributions, symptoms caused and potential of damage. Hence, the the present investigation was undertaken to study the pot culture experiment was conducted to pathogenicity of different inoculum levels of potato cyst nematodes on potato under polyhouse condition.

\section{Materials and Methods}

\section{Collection of root exudates}

The quality tubers of a potato cyst nematodes susceptible potato cv. Kufri Jyoti was sown in pots of $1 \mathrm{~kg}$ capacity filled with sterilized pot mixture soil (1:1:2 Farm yard manure: Sand: Red soil) in a polyhouse.

After establishment of the seedlings $15-20$ days after sowing the seedling was pulled out and washed thoroughly and transferred into $500 \mathrm{ml}$ beaker containing $200 \mathrm{ml}$ of tap water for incubation $24 \mathrm{hrs}$ at $20-25^{\circ} \mathrm{C}$ in the dark (Only the root system is immersed in the water).

Then the root exudates were filtered through a Whatman No.1 filter paper for getting a clear suspension and consider as a $100 \%$ concentration. Stored at $4^{\circ} \mathrm{C}$ and used as hatching agent described by European and Mediterranean Plant Protection Organization (2013).

\section{Collection of second stage juveniles from cysts}

For extraction of cysts, the soil samples were collected from potato fields having previous history of mixed population of potato cyst nematode, G. rostochiensis and G. pallida infestation. Then the soil samples were shade dried and then cysts were extracted using Fenwick can method (Fenwick 1940).

For hatching of potato cyst nematodes the root exudates were collected from 25-30 day old potato plants of cv. Kufri Jyoti grown in pots. Second stage juveniles were obtained from cysts pre soaked for one week in distilled water and then cysts were placed in the root exudates and kept at $18-22^{\circ} \mathrm{C}$ up to the hatching. The freshly harvested juveniles were used for further studies. 


\section{Pathogenicity of Globodera spp. on potato cv. Kufri Jyoti}

The experiment was conducted in polyhouse facility of Horticulture Research Station, Udhagamandalam, Tamil Nadu at a temperature of $17-25^{\circ} \mathrm{C}$. The present study was conducted during 2018. The experimental site is located at an altitude of $2140 \mathrm{~m}$ above MSL at $11^{\circ} 24^{\prime} \mathrm{N}$ latitude and longitude $74^{\circ} 4^{\prime} \mathrm{E}$.

The pot culture experiments were conducted under polyhouse condition with five treatments and four replications in a Completely Randomized Design. Plastic pots of five $\mathrm{kg}$ capacity were selected and filled with sterilized pot mixture soil (1:1:2 Farm yard manure: Sand: Red soil). The equal size of quality tubers were obtained from ICARCPRS, Muthorai, Udhagamandalam. Healthy tubers of susceptible cv. Kufri Jyoti were sown in pots. After establishment of the seedlings at 20 days after sowing different populations $(0,10,100,1000$ and 10,000) of freshly hatched second stage juveniles $\left(\mathrm{J}_{2}\right)$ of Globodera spp. per plant were inoculated through making 4-5 holes near the rhizosphere of each seedling. After inoculation, the holes were closed with sterilized soil followed by light irrigation and uninoculated plants were treated as control. The plants were regularly watered until their harvesting.

The experiment was terminated after 90 days of inoculations and observations on plant growth parameters, tuber yield, potato cyst nematode index and nematode population per plant was recorded. For interpretation of results, the reduction in plant growth was calculated in terms of percentage dry weight reduction. During the experimental period external symptoms of nematode infestation on plants were also recorded. Potato cyst nematodes index was determined using 1-4 grades, grade $1=$ no females/inch root, $2=1$ females/inch root, $3=5$ females/inch root and $4=>10$ females/inch root was given as per Grainger's test (Grainger, 1952). Potato cyst nematodes were extracted using Fenwick can method (Fenwick 1940) whereas numbers of juveniles were extracted from soil using Cobb's sieving and Decanting method followed by Modified Baermann's funnel technique. The nematode population in roots was determined by staining roots with acid fuchsin lactophenol stain (Beth et al., 1941). The multiplication rate of nematode was determined by calculating the reproduction factor $(\mathrm{Rf}=\mathrm{Pf} / \mathrm{Pi})$ where $\mathrm{Pf}$ represented the final population and $\mathrm{Pi}$ is the initial population of nematode. The data was analyzed statistically by applying the technique of analysis of variance (ANOVA). Mean values was calculated at 5\% significance level.

\section{Results and Discussion}

After eight weeks of inoculation, Globodera spp. exhibited some visible symptoms were observed in infested plants inoculated with 1000 and $10,000 \mathrm{~J}_{2} /$ plant. The result showed that, the potato cyst nematode Index was highest 4.0 at inoculum level of 10,000 juveniles and 1.75 at 10 juveniles per plant. The results of host infestation were recorded in terms of potato cyst nematode index which was directly proportional to the level of inoculum. The final root population of Globodera spp. was highest 905.40 females/plant at the highest inoculum level of $10,000 \mathrm{~J}_{2}$. However, the reproduction factor was highest 215.61 with the lowest inoculum level of $10 \mathrm{~J}_{2}$ per plant. The reproduction factor was 118.42, 47.71 and 22.02 respectively with the initial inoculum levels of 100,1000 and $10,000 \mathrm{~J}_{2}$ per plant. Our findings confirm earlier results reported by Chitwood (1948) showed that a heavily infested plant with $50 \mathrm{~g}$ of root would support 
60,000 females affect the growth and yield. Differences in environmental conditions, length of the potato growth cycle and differences in the cultivars may reflect on differences in the reproduction rates of the nematode. The results of our study revealed that, the total population was highest in the plants inoculated with $10,000 \mathrm{~J}_{2} /$ plant and lowest in those inoculated with $100 \mathrm{~J}_{2} /$ plant Table 1. A significant linear relationship was found between the initial and final population of Globodera spp. whereas, reproduction factor was significantly reduced with an increased inoculum levels. This decline trend of reproduction factor suggested a density dependent phenomenon.

The data presented in Table 2 clearly showed that with an increase in inoculum levels (except 0 and $10 \mathrm{~J}_{2} /$ plant) of Globodera spp. there was a corresponding reduction in all the plant growth parameters viz. plant height, fresh weight, dry weight and yield, however, the inoculum level of $10 \mathrm{~J}_{2} /$ plant did not show any significant variation in plant growth characters and all the characters were found on par with uninoculated plants. The highest reduction in plant growth was recorded at a level of $10,000 \mathrm{~J}_{2} / \mathrm{kg}$ soil and the minimum was recorded at a level of $100 \mathrm{~J} / 2 \mathrm{~kg}$ soil were as $1000 \mathrm{~J}_{2} /$ plant recorded as an Economic Threshold Level. Inoculation of $1000 \mathrm{~J}_{2} /$ plant showed 40.60, 32.00, 40.07 and 70.20 per cent reduction in plant height, fresh weight, dry weight and yield per plant respectively compared to uninoculated control.

The results of our study was in agreement with Sivakumar (1994) who observed that, the, economic threshold level at $1000 \mathrm{~J}_{2} /$ pot, which caused significant yield reduction by Meloidogyne hapla on carrot. In our study the plant growth was significantly different between 100 and $1000 \mathrm{~J}_{2}$ inoculated plants. The maximum of 87.35 per cent yield reduction was recorded, at an inoculum level of $10,000 \mathrm{~J}_{2} /$ plant followed by 70.19 and 26.99 per cent at a levels of 1000 and 100 $\mathrm{J}_{2}$ /plant respectively (Fig. 1). The relationship between the initial population and root weight was highly significant and negatively related.

The nematode infected plants above inoculum level of $1000 \mathrm{~J}_{2} /$ plant was poor in vigor, unhealthy in appearance and showed severe stunted growth. Affected plants also exhibited yellowing, premature drying, shedding of leaves like symptoms with reduced size and number of tubers. The root system becomes less developed and plants produce a greater amount of lateral roots, leading to overall decreased plant growth and premature death of plant. The presence of sphere shaped white and yellow females were also noticed on the surface of root hairs.

The progressive decrease in plant growth with increasing inoculum levels of nematodes has also been reported by Trudgill et al., (1975). The results of our study was in agreement with Grainger (1951) who observed that potato cyst nematode decreased the growth and weight of new tubers produced by potato cv. Epicure by more than $70 \%$ and infested plants were smaller and senesced earlier than uninfected plant.

Trudgill (1968) showed that growth of potato roots invaded by nematode larvae is markedly slower than uninoculated plants as Evans (1969) showed that roots were invaded before shoots emergence, recording more than 2000 larvae per $\mathrm{g}$ of root at only $60 \%$ emergence i.e.33 days after planting.

Infested plants were not only smaller, but also senesced earlier than lightly infested plants, as observed by Grainger (1951) but conflicting with the observations of Seinhorst and Den (1971) who suggested that nematode infestation delayed senescence. 
Table.1 Effect of different inoculum levels of G. rostochiensis and G. pallida on nematode multiplication

\begin{tabular}{|c|c|c|c|c|c|c|}
\hline \multirow{2}{*}{$\underset{(\mathbf{P i})}{\text { Inoculum level }}$} & \multicolumn{4}{|c|}{ Nematode population } & \multirow{2}{*}{$\begin{array}{c}\mathbf{R F}= \\
(\mathbf{P f} / \mathbf{P i})\end{array}$} & \multirow{2}{*}{$\begin{array}{c}\text { PCN Index as per } \\
\text { Grainger's test } \\
\text { No. of females/linear inch } \\
\text { root }\end{array}$} \\
\hline & $\begin{array}{c}\text { Soil population/ } \\
5 \mathrm{~kg} \\
\text { (a) }\end{array}$ & $\begin{array}{c}\text { Total root } \\
\text { population/ plant } \\
\text { (b) }\end{array}$ & $\begin{array}{l}\text { No. of eggs per } \\
\text { cyst (c) }\end{array}$ & $\begin{array}{l}\text { Final Population } \\
\text { (Pf) }[\mathbf{a}+(\mathbf{b} \times \mathbf{c})]\end{array}$ & & \\
\hline $\begin{array}{l}\text { O uninoculted } \\
\text { control }\end{array}$ & 0 & 0 & 0 & 0 & 0 & 1.00 \\
\hline $\begin{array}{l}10 \text { second stage } \\
\text { juveniles/plant }\end{array}$ & 2.50 & 7.10 & 303.33 & 2156.14 & 215.61 & 1.75 \\
\hline $\begin{array}{l}100 \text { second stage } \\
\text { juveniles/plant }\end{array}$ & 47.45 & 40.30 & 213.56 & 11842.32 & 118.42 & 2.75 \\
\hline $\begin{array}{l}1000 \text { second stage } \\
\text { juveniles/plant }\end{array}$ & 450.40 & 325.5 & 145.20 & 47713.00 & 47.71 & 5.00 \\
\hline $\begin{array}{l}10,000 \text { second stage } \\
\text { juveniles/plant }\end{array}$ & 778.50 & 905.40 & 176.42 & 220189.80 & 22.02 & 5.00 \\
\hline SE $(d)$ & 0.0026 & 4.3019 & 3.9110 & - & - & 0.2236 \\
\hline $\mathrm{CD}(\mathrm{p}=0.05)$ & 0.0055 & 9.1693 & 8.5213 & - & - & 0.4766 \\
\hline
\end{tabular}

Table.2 Effect of different inoculum levels of G. rostochiensis and G. pallida on the plant growth characters

\begin{tabular}{|c|c|c|c|c|c|c|c|c|c|c|}
\hline \multirow{2}{*}{$\begin{array}{c}\text { Inoculum level } \\
(\mathbf{P i})\end{array}$} & \multicolumn{3}{|c|}{ Plant height (cm) } & \multicolumn{3}{|c|}{ Plant fresh weight (g) } & \multicolumn{3}{|c|}{ Plant dry weight (g) } & \multirow{2}{*}{$\begin{array}{l}\text { Yield }(\mathrm{g}) \\
\text { per plant }\end{array}$} \\
\hline & Shoot & Root & Total & Shoot & Root & Total & Shoot & Root & Total & \\
\hline 10 second stage juveniles/plant & $\begin{array}{l}60.86 \\
(2.58)\end{array}$ & $\begin{array}{l}34.41 \\
(3.67)\end{array}$ & 95.27 & $\begin{array}{c}205.72 \\
(2.10)\end{array}$ & $\begin{array}{l}22.48 \\
(6.49)\end{array}$ & 228.20 & $\begin{array}{l}24.17 \\
(6.57)\end{array}$ & $\begin{array}{c}5.02 \\
(25.07)\end{array}$ & 29.19 & $\begin{array}{l}650.73 \\
(6.05)\end{array}$ \\
\hline 100 second stage juveniles/plant & $\begin{array}{c}51.92 \\
(16.89)\end{array}$ & $\begin{array}{c}21.69 \\
(39.28)\end{array}$ & 73.61 & $\begin{array}{l}177.61 \\
(15.48)\end{array}$ & $\begin{array}{l}17.60 \\
(26.79)\end{array}$ & 195.21 & $\begin{array}{c}20.09 \\
(22.34)\end{array}$ & $\begin{array}{c}4.01 \\
(40.15)\end{array}$ & 24.10 & $\begin{array}{l}505.65 \\
(26.99)\end{array}$ \\
\hline 1000 second stage juveniles/plant & $\begin{array}{c}44.56 \\
(28.66)\end{array}$ & $\begin{array}{c}13.76 \\
(61.48)\end{array}$ & 58.32 & $\begin{array}{l}143.49 \\
(31.72)\end{array}$ & $\begin{array}{c}15.76 \\
(34.44)\end{array}$ & 159.25 & $\begin{array}{c}15.76 \\
(39.08)\end{array}$ & $\begin{array}{c}3.76 \\
(43.89)\end{array}$ & 19.52 & $\begin{array}{l}206.50 \\
(70.19)\end{array}$ \\
\hline SE(d) & 0.0647 & 0.0681 & - & 0.1747 & 0.0721 & - & 0.0552 & 0.0248 & - & 0.2380 \\
\hline $\mathrm{CD}(\mathrm{p}=\mathbf{0 . 0 5})$ & 0.1380 & 0.1452 & - & 0.3723 & 0.1536 & - & 0.1177 & 0.0528 & - & 0.5073 \\
\hline
\end{tabular}

(Figures in parentheses indicate the per cent decrease over uninoculated control 
Fig.1 Effect of different inoculum levels of Globodera spp. on the plant height and yield

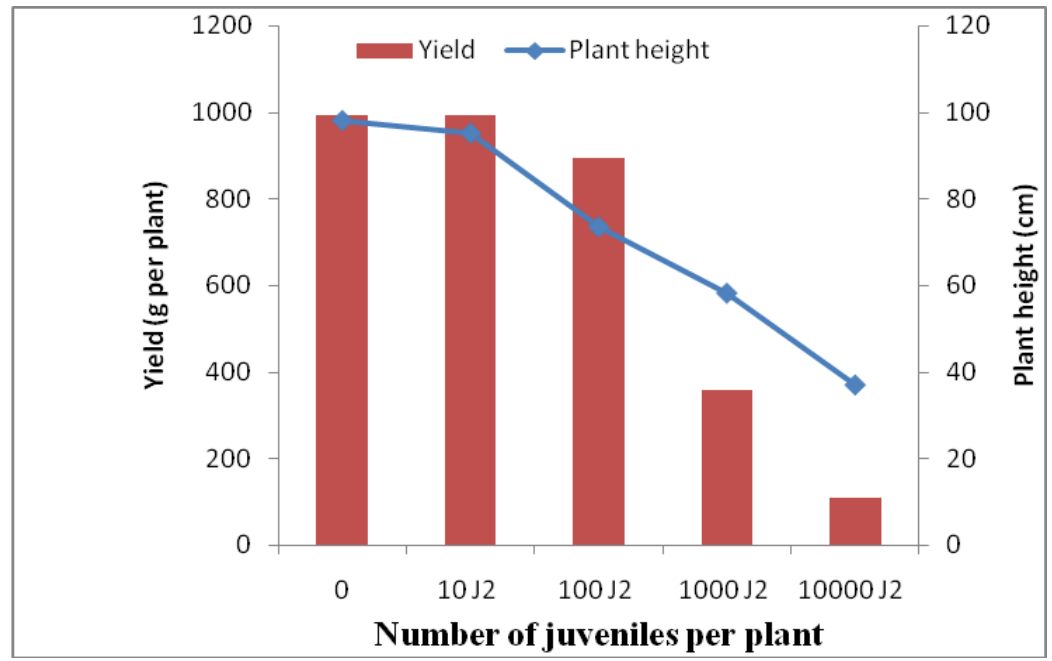

\section{Acknowledgement}

The authors would gratefully acknowledge the Horticultural Research Station, Udhagamandalam 643001 and Department of Nematology, Tamil Nadu Agricultural University, Coimbatore - 641003 for providing necessary facility to carry out the present work.

\section{References}

Beth, R. A. 1941. Penetration of projectiles in concrete. PPAB Interim Report, Washington, DC.

Chitwood, A. G. 1948. Feldmesser J. Golden nematode population studies. Helmithological Society of Washington. 1948; 15: 43-55.

Evans, K. 1969. Changes in a Heterodera rostochiensis population through the growing season. Annals of Applied Biology, 64, 31-41.

Fenwick, D. W. (1940). Methods for the recovery and counting of cysts of Heterodera schachtii from soil. Journal of Helminthology. 18(4), 155172.

Grainger, J. 1951. The Golden Eelworm. Research Bulletin 10 of the West of
Scotland Agricultural College, Auchincruive, Ayr.

Jones, F. G. W. 1961. The potato root eelworm, Heterodera rostochiensis in India. Current Science. 30: 187.

Mhatre, P. H., Divya, K. L., Venkatasalam, E. P., Bairwa, A., Sudha R and Berliner J. 2019. Potato cyst nematode: A hidden enemy of potato cultivation in hills. Bhartiya Krishi Anusandhan Patrika, 34(1), 50-53.

Sasser, J. N and Freckman D. W. 1987. World perspective on nematology. In: Vistas on Nematology Ed. J.A. Veech and D.W. Dickson, Printed by Society of Nematologists, Maryland, USA. 509: 7-14.

Seenivasan, N. 2017. Status of potato cyst nematodes Globoderaspp infection on potato at Kodaikanal hill of Tamil Nadu, India and yield loss estimation. Journal of Entomology and Zoology Studies, 5(5), 268-272

Seinhorst, J. W and Den, O. H. 1971. The relation between density of Heteroderarosto- chiensis and growth and yield of two potato varieties. Nematologica.17: 347-369.

Singh, M., Ganguly, S and Ganguly, A. K. 2010. Record of potato cyst nematode, 
Globodera rostochiensis and $G$. pallida in Shimla, Himachal Pradesh, India. Indian Journal of Nematology., 40: 96-102.

Sivakumar, M. 1994 Bio ecology and Non chemical Management of Northern root Knot Nematode Meloidogyne hapla in carrot. Ph.D. thesis submitted to TNAU, Coimbatore, $92 \mathrm{p}$.

Thangaraju, D. 1983. Distribution of potato cyst nematodes in Kodaikanal hills, Madurai district, Tamil Nadu. Indian Journal of Nematology. 13(2), 222223.

Trudgill, D. L., Elliott, M. J., Evans, K and Phillips, M. S. 2003. The white potato cyst nematode (Globodera pallida) - a critical analysis of the threat in Britain. Annals of Applied Biology. 143: 73-80.

Trudgill, D. L., Evans, K and Parrott, D. M. 1975. Effects of potato cystnematodes on potato plants. Nematologica. 21:169-182.

Trudgill, D. L. 1968. The effect of environment on sex determination in Heterodera rostochiensis. Ph.D. Thesis, University of London. 188.

Trudgill, D. L. 1986. Yield losses caused by potato cyst nematodes: a review of the current position in Britain and prospects for improvements. Annals of Applied Biology, 108(1), 181-198.

\section{How to cite this article:}

Vanitha, S., A. Shanthi, Priyank Hanuman Mhatre, B. Anita, P. Kalaiarasan, P. Marimuthu and Muthamilan, M. 2019. Studies on Pathogenicity of Potato cyst Nematode, Globodera rostochiensis and G. pallida on Potato. Int.J.Curr.Microbiol.App.Sci. 8(06): 624-630. doi: https://doi.org/10.20546/ijcmas.2019.806.072 